\title{
EXPLAINING THE CONCEPT AND DIMENSIONS OF PROFESSIONAL FUNCTIONS IN ONLINE LEARNING SYSTEM OF MEDICAL SCIENCES: A QUALITATIVE CONTENT ANALYSIS
}

\author{
Dr. Zohrehsadat MIRMOGHTADAIE \\ ORCID: 0000-0002-3267-9121 \\ Department of virtualization in Medical Education, Virtual School \\ Tehran University of Medical Sciences \\ Tehran, IRAN \\ Dr. Soleiman AHMADY \\ ORCID: 0000-0003-00551-6068 \\ Department of Medical Education \\ Shahid Beheshti University of Medical Sciences \\ Tehran, IRAN \\ Dr. Noushin KOHAN \\ ORCID: 0000-0002-8163-742X \\ Department of Medical Education \\ Virtual University of Medical Sciences \\ Tehran, IRAN \\ Dr. Tayebeh RAKHSHANI \\ ORCID ID: 0000-0003-3693-8802 \\ Nutrition Research Center, Department of Public Health \\ Shiraz University of Medical Sciences \\ Shiraz, IRAN
}

Received: 08/09//2018 Accepted: 04/03/2019

\begin{abstract}
The increasing growth of technology affects all aspects of life, including the system of education, and requires the implementation of a new education system. Since Electronic-learning (E-L) is a new and mutated form of education in Iran, its professional functions approach is different from that of traditional education. The present article aims to explain the concept and dimensions of professional functions in this field. Through a qualitative study, method and data source triangulation were used. To do so, the data sources were the professors, scholars, students, and graduates of this educational system in the field of medical sciences. To triangulate the methods, in-depth semi-structured interviews as well as focus groups, note-taking and reminders were used. The purposeful sampling consisted of 10 professors and scholars. Fifteen students and graduates participated in the four-session focus group discussions purposeful, and the sample consisted of 10 professors and scholars as well as seven students and graduates, and a total of 15 students and graduates were willing to participate in the focus group discussions. Inductive content analysis was used for the analysis of data. Three themes arose from the study as follows: E-learning prerequisites, E-Leaning enabling factors, and E-Learning obstacles. Each of the themes is explained along with the relevant categories and subcategories.

Discovering the dimensions and elements affecting professional functions in the E-Lsystem of medical sciences, this study provided documented meanings and dimensions of this phenomenon beyond the conventional sense. These dimensions can have direct or indirect impacts on professional functions in this field.
\end{abstract}

Keywords: Medical professionalism, online education, qualitative research. 


\section{INTRODUCTION}

The digital and Internet era has the potential for significant changes and dilemmas (Thang et al., 2015). The new spaces in which knowledge and information flow are very different from those experienced by previous generations so that the way knowledge is acquired has undergone a fundamental transformation. According to Wayne, working with a computer requires a different type of thinking because it grows hypertext minds and parallelizes, not makes sequential, the mental structures of individuals (Porter, 2003; Higgs, 2012)

The increasing growth of technology affects all aspects of life, especially in the area of education, and makes necessary the implementation of an innovative educational system (Rhema\& Miliszewska, 2010). Establishment of this educational system, also called E-Learning systems, is based on technology. Considering the benefits of E-Learning in different levels of medical sciences, we can see that the demand for these courses in universities is on the rise (Ahmad, 2010). This kind of education is new in Iran and has been used in medical science education in recent years.

It is no more the question of whether the technology should or should not integrate into higher education, but what is important is how to involve it in the field of medical education and to plan to take advantage of this phenomenon (Beqiri, Chase \& Bishka, 2009). Like any other technology, E-Learning will undoubtedly bring new challenges, one of which is ethical issues, so that in 2001 the inclusion of ethical issues in the field of E-Learning was included on the agenda of the European Union (Communities, 2001). The philosophy of education is morality, and education without morality may lead to the prevalence of immorality in societies. As E-Learning is a new method of learning and teaching, the concept of professional functions is presented in another form. Firstly, as E-Learning is not limited to a specific place and time and includes a wide range, ethical issues are also presented universal; i.e., comprehensive ethics that is not limited to a specific religion, civilization, culture, time and place (Chickowski, 2005). Secondly, the concept of professional functions has changed from traditional to modern. In this approach, what matters is that the implementation of ethical norms is not only for the acquisition of professional identity, but it is a need for success in global markets (Svensson, 2006).

Since the E-Learning system is not one-dimensional, the concept of professional functions is based on ethical issues in the two areas of education and technology. It can function in different cultures and be universal, and it can be expected to be advertised and promoted all over the world (Busikova \& Melicherikova, 2013). The rapid advances in knowledge over the past three decades have changed the nature of all professions, and sole reliance on expertise might eliminate the unique nature of a profession (Oermann, 1994). Uncertainty and ambiguity are the characteristics of the virtual learning system Entering this area, either as a learner or a teacher, requires the individuals to have the least abilities related to functional knowledge and attitudes so that they could both enhance their existential traits and keep the organization in a steady scientific position (Powell, Rabbitt $\&$ Kennedy,2014). The success of any educational system depends more heavily on professional knowledge and skills of the stakeholders of that system. In e-learning, quality assurance requires a full range of professional as well as other specific competencies, and without knowing the education and sciences related to technology, no proper steps could be taken in this direction (Blin\&Munro, 2008).

Professionalism is a multidimensional and complicated concept, and professionalism in the E-Learning system is a more complicated one because educational contexts and learning environments face emerging challenges that require the people who are specialized in both areas of education and technology (Ellaway, 2011). Some studies suggested that new educational environments would bring about a lot of moral riddles that would require proper analysis and appropriate responses. If moral behavior did not occur in the cyberspace, it would be due to the failure in one of the following components: moral sensitivity, moral judgment, moral motivation, and moral character (Lucas, 2017). E-Learning is a field in education that is expanding rapidly. Due to the rapid growth of this new field, it is desirable to build the basis of this learning system on a strong moral foundation at the very beginning of its development. If there is a professional E-Learning system, a bright future can be imagined for this field. Being aware of the views and understanding of the experts, students and graduates of this field about the concept of professional functions of the E-Learning system and the importance and necessity of addressing it is a prerequisite for appropriate policies and plans in this area. A review of various studies on professional functions and its dimensions showed that these studies had often been carried out quantitatively and addressed one or more aspects of the issue (Dobrow 
\& Higgins,2005; Gragg et al., 2016). There is little qualitative research exploring in depth the concept of professional functions and its dimensions in the E-Lsystem of medical sciences.

Regarding the importance of medical science disciplines and observing ethics in this field, we aimed to explain the concept of professional functions and its dimensions in the E-Learning system of medical sciences. Indeed, the qualitative approach is exceptionally well suited for investigation of professional function in health research where complex professional issues are often best explored through this approach. The present article aims to explain the concept and dimensions of professional functions in this field.So the research question was: What are the Concept and Dimensions of Professional Functions in Online Learning System of Medical Sciences from the viewpoints of stakeholders?

\section{METHODOLOGY}

In this research, qualitative content analysis is defined as a research method for the subjective interpretation of the content of text data through the systematic classification process of coding and identifying themes or patterns. Although Practices and philosophies of content analysis vary between academic disciplines, they all involve systematic reading or observation of texts or artifacts which are assigned labels (sometimes called codes) to indicate the presence of unusual, meaningful pieces of content

Method and data source triangulation were used. To do so, the data sources were the professors, scholars, students, and graduates of this educational system in the field of medical sciences. To triangulate the methods, in-depth semi-structured interviews as well as focus groups, note-taking and reminders were used.

\section{Interview}

The sampling was purposeful, and the sample consisted of 10 professors and scholars as well as seven students and graduates. Interviewing continued, until the data from the interviews were consistently duplicated. There appeared to be saturation of data as no new information was gained from the last interviews. After obtaining informed consent from the participant, the interviews began with unstructured questions, some probing questions were also in the interview protocol to ensure interviewees' perceptions regarding the concept of professional functions in the online learning environment. Each interview lasted 45 to 60 minutes on average. Following data transcription, inductive content analysis, defined by Elo and Kyngas (2008) was used. According to Elo and Kyngas, content analysis has three main stages: data preparation with the selection of the unit of analysis; organizing the data including open coding, creating categories and abstraction; and finally reporting the results (2008).

\section{Focus Group}

The focus group discussions conducted for this study allowed an opportunity to explore those issues further. A total of 15 students and graduates were willing to participate in the four 1.5-hour sessions focus group discussions. Participants were recruited through the "snowball" method. Before the session, participants completed a brief self-administered written questionnaire to assess demographic data.

The focus group guide included questions about the participant's experiences about the concept and dimensions of professional functions. All sessions were audiotaped and transcribed. Members of the research team debriefed following each focus group session, and focus groups were continued until it was agreed that thematic saturation was reached. Three members of the research team independently analyzed each transcript, using a content analysis approach. Data from the notes and transcripts were reviewed, and codes were generated. Codes were then analyzed and categorized into themes independently by investigators and discussed, resulting in full agreement.

\section{Trustworthiness of Qualitative Data}

Numerous frameworks have been developed to evaluate the rigor or assess the trustworthiness of qualitative data (Guba, 1981; Lincoln \& Guba, 1985) and strategies for establishing credibility, transferability, 
dependability, and confirmability. In this study, the credibility of the qualitative findings was ensured by using member check and immersion techniques as well as the ongoing engagement of the researchers with the data and also participation in similar congresses. Also, in order to ensure the accuracy of the data, the people who had the experience of conducting qualitative research were asked (peer check) to review the initial interviews, coding, and categories.

\section{Ethical Considerations}

The study was approved by the Ethics Committee of Shahid Beheshti University of Medical Sciences in Iran. The stakeholders were informed of the objectives of the study and the participation in the study was voluntary.

\section{RESULTS}

A total of 15 postgraduate students and teachers participated in 4 focus groups. The mean age of the focus group participants was 32.6 years. A total of 17 postgraduate students and teachers participated in 20 interviews. The mean age of interview participants was 37.5 years. The distribution of sampling criteria is presented in Table 1.

Table 1. Distribution of sampling criteria in participant

\begin{tabular}{|c|c|c|c|c|}
\hline Participant & Sex & Age & Major & University Location \\
\hline \multicolumn{5}{|l|}{ Interview } \\
\hline P1 & Male & 32 & $\begin{array}{l}\text { eLearning in medical } \\
\text { education }\end{array}$ & Shahid Beheshti University of Medical Science \\
\hline $\mathrm{P} 2$ & Male & 33 & $\begin{array}{l}\text { eLearning in medical } \\
\text { education }\end{array}$ & Shahid Beheshti University of Medical Science \\
\hline P3 & Male & 45 & $\begin{array}{l}\text { eLearning in medical } \\
\text { education }\end{array}$ & Shiraz University of Medical Science \\
\hline P4 & Female & 41 & $\begin{array}{l}\text { eLearning in Medical } \\
\text { Education }\end{array}$ & Tehran University of Medical Science \\
\hline P5 & Female & 28 & Medical Education & Shahid Beheshti University of Medical Science \\
\hline P6 & Female & 33 & $\begin{array}{l}\text { eLearning in medical } \\
\text { education }\end{array}$ & Tehran University of Medical Science \\
\hline P7 & Female & 40 & Medical Education & Shiraz University of Medical Science \\
\hline P8 & Female & 36 & Medical Education & Tehran University of Medical Science \\
\hline P9 & Female & 42 & $\begin{array}{l}\text { eLearning in medical } \\
\text { education }\end{array}$ & Shahid Beheshti University of Medical Science \\
\hline P10 & Female & 45 & $\begin{array}{l}\text { eLearning in medical } \\
\text { education }\end{array}$ & Shahid Beheshti University of Medical Science \\
\hline P11 & Female & 28 & $\begin{array}{l}\text { eLearning in medical } \\
\text { education }\end{array}$ & Tehran University of Medical Science \\
\hline P12 & Female & 28 & Medical education & Iran University of Medical Science \\
\hline P13 & Female & 36 & Medical education & Tehran University of Medical Science \\
\hline P14 & Male & 40 & Medical education & Shahid Beheshti University of Medical Science \\
\hline P15 & Male & 39 & Medical education & Tehran University of Medical Science \\
\hline P16 & Male & 43 & Medical education & Shahid Beheshti University of Medical Science \\
\hline P17 & Male & 48 & $\begin{array}{c}\text { eLearning in medical } \\
\text { education }\end{array}$ & Tehran University of Medical Science \\
\hline
\end{tabular}




\begin{tabular}{|c|c|c|c|c|}
\hline Focus Group & & & & \\
\hline P1 & Male & 38 & $\begin{array}{l}\text { eLearning in medical } \\
\text { education }\end{array}$ & Shahid Beheshti University of Medical Science \\
\hline P2 & Male & 32 & $\begin{array}{l}\text { eLearning in medical } \\
\text { education }\end{array}$ & Shahid Beheshti University of Medical Science \\
\hline P3 & Male & 31 & $\begin{array}{l}\text { eLearning in medical } \\
\text { education }\end{array}$ & Shiraz University of Medical Science \\
\hline P4 & Female & 31 & $\begin{array}{l}\text { eLearning in Medical } \\
\text { Education }\end{array}$ & Tehran University of Medical Science \\
\hline P5 & Female & 28 & Medical Education & Shahid Beheshti University of Medical Science \\
\hline P6 & Female & 33 & $\begin{array}{l}\text { eLearning in medical } \\
\text { education }\end{array}$ & Tehran University of Medical Science \\
\hline P7 & Female & 29 & Medical Education & Shiraz University of Medical Science \\
\hline P8 & Female & 34 & Medical Education & Tehran University of Medical Science \\
\hline P9 & Female & 44 & $\begin{array}{l}\text { eLearning in medical } \\
\text { education }\end{array}$ & Shahid Beheshti University of Medical Science \\
\hline P10 & Female & 32 & $\begin{array}{l}\text { eLearning in medical } \\
\text { education }\end{array}$ & Shahid Beheshti University of Medical Science \\
\hline P11 & Female & 29 & $\begin{array}{l}\text { eLearning in medical } \\
\text { education }\end{array}$ & Tehran University of Medical Science \\
\hline P12 & Female & 27 & Medical education & Tehran University of Medical Science \\
\hline P13 & Female & 31 & Medical education & Tehran University of Medical Science \\
\hline P14 & Male & 42 & Medical education & Shahid Beheshti University of Medical Science \\
\hline P15 & Male & 29 & Medical education & Tehran University of Medical Science \\
\hline
\end{tabular}

The result of this study was three themes as follows: "E-L Prerequisites, "E-L Enabling Factors" and "E-L Obstacles "and each of the themes are explained below along with the relevant categories.

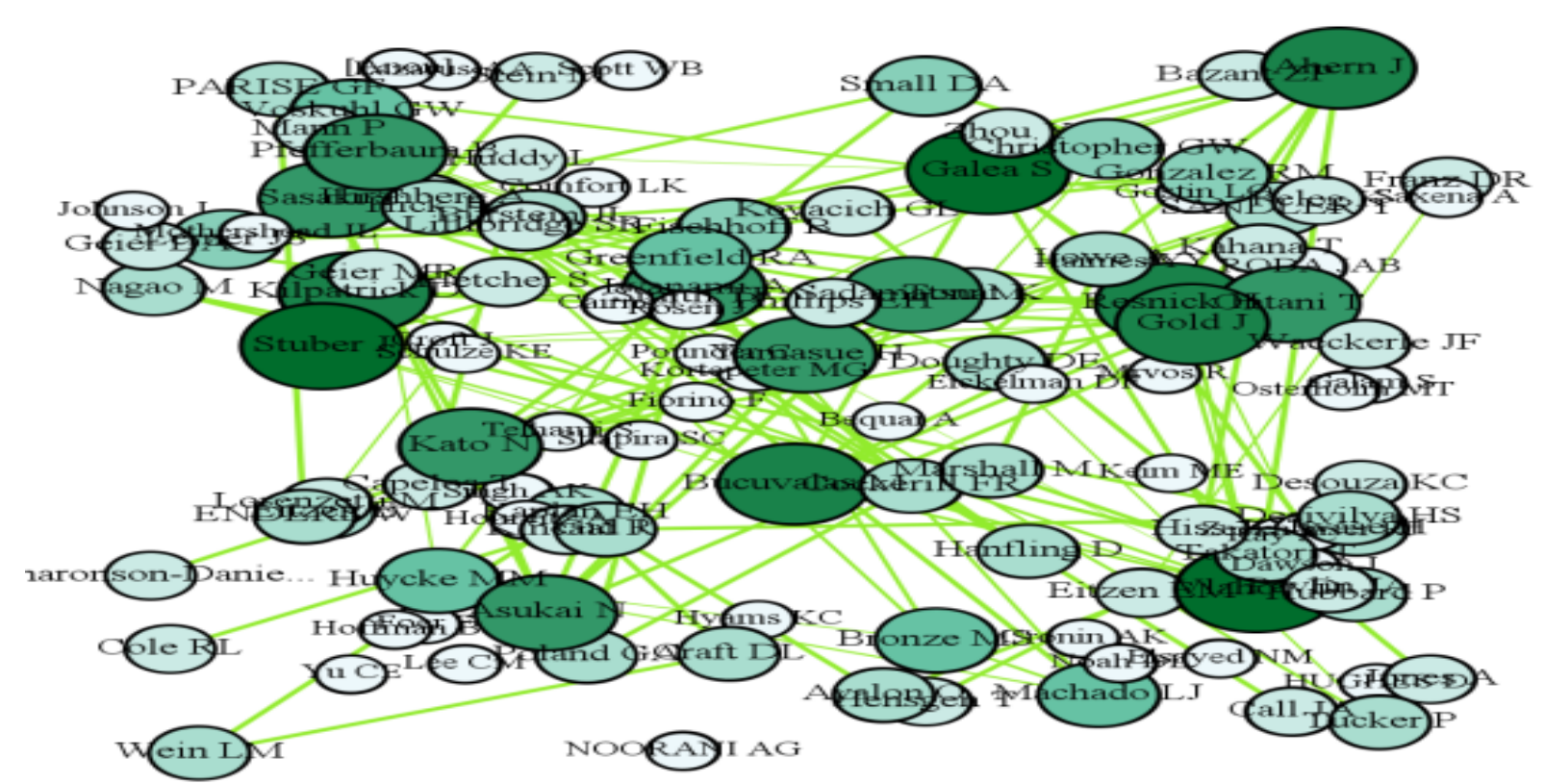

Figure 1. Conceptual map of the themes 


\section{E-L Prerequisite}

This theme includes two categories of individual factors and supportive environment. Individual factors refer to issues such as students' and teachers' competencies in E-L environments, especially computer literacy. Students' attitudes and their sense of presence in the social environment are other influential factors.

The second category is the supportive environment that includes Institute Value, Technical Infrastructures, and Role Awareness in the virtual environment and the existence of ethical codes and rules.

Table2. Statements of the participants, subcategories, and categories derived from the E-L Prerequisite theme

\begin{tabular}{|c|c|}
\hline & E-L prerequisite \\
\hline Categories & Sub Categories \\
\hline \multirow{9}{*}{ Individual Factor } & E-student and E-teacher competencies \\
\hline & $\begin{array}{l}\text { "Any teaching requires the relevant teacher to have enough knowledge in that field. So does this } \\
\text { type of teaching. If you are not a specialist of the content you want to teach, you will not be able } \\
\text { to do the right job. On the other hand, you need to know the IT skills to figure out how to teach } \\
\text { well." }\end{array}$ \\
\hline & $\begin{array}{l}\text { "On the Internet, hundreds of new information pages open every day, and people should learn } \\
\text { how to select and read from among and how to study. The speed of reading and how to study } \\
\text { are important." }\end{array}$ \\
\hline & $\begin{array}{l}\text { "Critical thinking, creativity, problem-solving, and decision-making are all necessary for a } \\
\text { successful student, and I think a virtual student needs them more because he is developing } \\
\text { independently," }\end{array}$ \\
\hline & $\begin{array}{l}\text { "I think, both the virtual students and the instructors have to pass the ICDL courses before } \\
\text { enrollment to the course, and they need to have some experiences of working in such an } \\
\text { environment. Most students do not even know the databases." }\end{array}$ \\
\hline & Attitude and sense of community \\
\hline & $\begin{array}{l}\text { "In order to establish a deep and intimate relationship between the teacher and the student, they } \\
\text { should be in much contact with each other as if they were together for years." }\end{array}$ \\
\hline & $\begin{array}{l}\text { "If students collaborate, many problems in this area will be solved, and students do not go toward } \\
\text { plagiarism. They will not hide behind their profile picture, and the whole workflow goes far more } \\
\text { natural". }\end{array}$ \\
\hline & $\begin{array}{l}\text { "The E-Environment is a remote area. If the students and the instructors do not feel that they } \\
\text { interact with others and if they do not somehow feel present in a large community, the concept } \\
\text { of professional work is false." }\end{array}$ \\
\hline \multirow{9}{*}{$\begin{array}{l}\text { Supportive } \\
\text { Environment }\end{array}$} & Institute value \\
\hline & $\begin{array}{l}\text { "In an educational system of any type, values must be dominant. A value environment forces } \\
\text { people to act value-based". }\end{array}$ \\
\hline & Technical infrastructures \\
\hline & $\begin{array}{l}\text { Technical infrastructures are among the most effective factors that can help both the teachers } \\
\text { and the students to do well. If the speed of the Internet is low or the equipment is weak, it is like } \\
\text { a university class without a blackboard." }\end{array}$ \\
\hline & Role awareness and unity \\
\hline & $\begin{array}{l}\text { "A good university is the one where teamwork is common, and the members collaborate. So a } \\
\text { well-defined program, as well as coordination and student awareness of their roles in the virtual } \\
\text { environment, can help professionalize the system." }\end{array}$ \\
\hline & $\begin{array}{l}\text { "To have a safe and secure university, there must be harmonized rules and regulations in order for } \\
\text { both the students and the instructors. The rules follow the ethical pathway in the system." }\end{array}$ \\
\hline & Ethical codes \\
\hline & $\begin{array}{l}\text { "Before entering these universities, everyone should first get familiar with the rules of these } \\
\text { universities and, secondly, they will be committed to complying with the rules. If people are into } \\
\text { the frameworks, it seems that they will make fewer mistakes. Of course, the rules should have an } \\
\text { executive guarantee." }\end{array}$ \\
\hline
\end{tabular}




\section{Enabling Factors}

This category consists of two sub-categories: 1 . Individual dimensions that include personal characteristics, Ethical and Professional Identities, and Intellectual Growth. 2. Social factors.

Table 3. Statements of the participants, subcategories, and categories derived from the Enabling Factors Theme

\begin{tabular}{|c|c|}
\hline & Enabling Factors \\
\hline Categories & Sub Categories \\
\hline \multirow{7}{*}{ Individual Dimensions } & Personal characteristic \\
\hline & $\begin{array}{l}\text { "E-L environments are constantly changing. They are frequently updated with much new } \\
\text { information. It is as if science changes every day. This needs both the teachers and the } \\
\text { students who enter this system to have a personality structure interested in this kind of } \\
\text { changes." }\end{array}$ \\
\hline & Intellectual growth \\
\hline & $\begin{array}{l}\text { "Regarding the philosophy of e-learning, if a student seeks self-learning, recognizes his own } \\
\text { needs and causes his self-empowering, it can be ensured that this E-Environment has reached } \\
\text { its own goal and philosophy." }\end{array}$ \\
\hline & Identity \\
\hline & $\begin{array}{l}\text { "In the virtual environment, anyone is free to cheat, use copyright, and do much immoral } \\
\text { work, but if the person's identity is formed and he is committed, there is at least such a hope } \\
\text { that he is less inclined to do so." }\end{array}$ \\
\hline & $\begin{array}{l}\text { "It is better that people with a cultural-religious identity enter into this system; I mean } \\
\text { students who have a cultural root since childhood. Although this might be impossible, it may } \\
\text { be partly achieved by an oral interview." }\end{array}$ \\
\hline \multirow{4}{*}{ Social Factor } & Organizational culture \\
\hline & $\begin{array}{l}\text { "All the values and organizational culture must be conveyed to the individuals. This peace } \\
\text { of mind cause them both to feel that they are in an organization with certain frameworks in } \\
\text { which any non-professional behavior can be asked for an explanation; so they act better." }\end{array}$ \\
\hline & Netiquette \\
\hline & $\begin{array}{l}\text { "In cyberspace, talking and text writing and even personal pictures must be polite and ethical, } \\
\text { which is itself a preventative factor in cybercrime." }\end{array}$ \\
\hline
\end{tabular}

\section{E-L Obstacles}

This class includes two sub-categories of Role Ambiguity and Inappropriate Situations. There are also two subcategories of Role Unawareness and Lack of Role Definition in the Role Ambiguity subclass. Besides, in the subclass of Inappropriate Situations, there are two categories of e-environment conditions and power of decision making. Insufficient Feedback and Lack of Law in Evaluation are the subcategories of Lack of evaluation System, as well. 
Table 4. Participants' statements, subcategories, and categories derived from the E-L obstacles theme

\begin{tabular}{|c|c|}
\hline & E-L Obstacles theme \\
\hline Categories & Sub Categories \\
\hline \multirow{4}{*}{ Role Ambiguity } & Role unawareness \\
\hline & $\begin{array}{l}\text { "Students and instructors who enter this area do not know exactly what their role is and } \\
\text { what they should do. The instructors are told they are mainly facilitators, not teachers, but } \\
\text { they do not know exactly how to play their role. The students are also told they are self- } \\
\text { directed learners, but they do not know exactly what it means. All of these can be harmful, } \\
\text { and the E-Learning system may go on without effective and specialized planning." }\end{array}$ \\
\hline & Lack of role definition \\
\hline & $\begin{array}{l}\text { "When I was an MSc student in the virtual environment, nobody explained to me how } \\
\text { different this kind of learning was with traditional education. Nobody at all said I had to be } \\
\text { as special as the people trained in traditional education." }\end{array}$ \\
\hline \multirow{4}{*}{ Inappropriate Situations } & E-environmental conditions \\
\hline & $\begin{array}{l}\text { "The virtual learning environment is a strange environment. Until you get into it, you } \\
\text { cannot comment on it. It is always changing, and you have to align yourself with it." }\end{array}$ \\
\hline & Power of decision making \\
\hline & $\begin{array}{l}\text { "Given the nature and sensitivity of this environment and the existence of thousands of } \\
\text { ways to become immoral, people in this area must have an understanding of its situations } \\
\text { and make the right decisions. The power of decision making is a great art for you." }\end{array}$ \\
\hline \multirow{4}{*}{ Lack of Evaluation System } & Lack of law in an evaluation \\
\hline & $\begin{array}{l}\text { "There is no legal requirement to monitor the work of our instructors and students } \\
\text { carefully. Who is called a professional in this system? If it is exactly determined according } \\
\text { to which list the students and instructors are evaluated and get a professional label, we will } \\
\text { be helped move forward to being ethical and professional." }\end{array}$ \\
\hline & Insufficient feedback \\
\hline & $\begin{array}{l}\text { "If I do not give feedback to my students about their work, how can they understand if their } \\
\text { work is going on correctly? How do I know if he is acquiring the necessary expertise? If the } \\
\text { feedbacks are timely and correct, the students are less likely to do unethical behaviors, } \\
\text { such as copyright, etc. Hence, they will naturally go toward morals and rightness." }\end{array}$ \\
\hline
\end{tabular}

\section{DISCUSSION AND CONCLUSION}

The rapid growth of science and technology along with the weakness of traditional ethical systems has raised the question of whether the new educational systems are committed to a quality based on moral logic and collective good. Regarding the globalization processes, what dimensions and components should we consider in order to move towards a professional E-Lsystem? The results of the research showed that prerequisites are among the critical dimensions of professional performance in online learning.

Professional performance refers to a set of required skills, including technical skills and high-level cognitive skills which are required by the instructor and the students (Pawlina, 2006; Hung \& Yuen, 2010). In his research on predictive factors for success in this field, Sawtelle considered some skills, including search and translation, to be significant (Moraveji et al., 2011; Lai, 2011). The present study helps to confirm this issue and addressed specialized, technical and pedagogical skills. Attitude and feeling of presence are among the most critical issues in this field. In 2003, it was shown in American universities that electronic learning systems undermined intellectual interaction, and the reason was said to be the lack of a sense of presence by the learners and the instructors. Today, the term "educational well-being" is used and it is argued that the feeling of security and positive attitude toward such an environment is effective in optimizing this system (Samdal, Wold \& Bronis, 1999). In the age of "cyber paradigm," the roles of instructors and students have significantly changed, and therefore, it is necessary to acquire the skills in this field (Sandholtz, 1997; Carril, Sanmamed \& Selles, 2013). On the other hand, the structure of the educational environment is an influential factor. Improving educational environments are themselves stimuli of moral behaviors (Garrett, Carnahan \& Lynch, 2013). 
Holt believed that further considerations needed to be designed and implemented to improve supportive environments (Holt \& Roff, 2004). The present study also referred to the role of supportive environments and considered the knowledge of the laws and governance in this area to be important. In 2015, a list of cybercrime cases was published, and it was shown that the reason for the increase in cheating in the cyberspace was the psychological distance and the low level of control over the students and their lack of knowledge about the rules of this field (Mishna et al., 2012). There are many traps in the cyberspace; each is a barrier to professional performance. Thus, knowing and understanding all the rules of this space can lead us to professionalism (Spinello, 2010). The inevitable necessities for having civilized societies are global thinking and universal living. Adherence to institutional values is one of the essential requirements for having an independent system. "Institutional value" was one of the subthemes found in the present study. Another theme found in this research was the enabling factors that have categories and subcategories. Personality is one of the factors that has recently been taken into consideration by E-Students and instructors, Davis is one of the researchers who paid particular attention to this issue, and believed that people who were in this system had to be extrovert, and he even anticipated specific personality tests for them (Davis \& Rose, 2007). In this research, personality and identity were also considered as reinforcing personal factors. Educational environments play an important role in gaining an identity. People in this system should know their position in order to acquire knowledge better. Identity is a broad concept and covers all aspects of individual, collective, national and transnational identity. The future world will be the field of a fight between two prestigious powers, i.e., globalization and identity. Another theme obtained in this research was E-obstacle. Role ambiguity was one of the categories discovered in the present research. In line with the results of this research, Salmon also stated in his book that there was no precise definition of roles in this field, and this unknowingness could be a significant barrier to learning (Salmon, 2004).

On the other hand, the learners in the E-Lsystem do not exactly know if the path ahead will improve their academic achievement or no. Hence, it is necessary for them to receive useful and right feedbacks in order to get aware of the quantity and quality of their knowledge (Lemley \& Lessig, 2000). Frayer believed that there was no difference between the views of the less experienced and highly experienced instructors (Beqiri, Chase \& Bishka, 2009). Providing appropriate feedbacks causes more interactions, but the concept of interaction in this area is of great importance. Interaction does not only refer to clicking and moving along pages, but a real interaction requires learner engagement to high-level skills (Lynch, 2002). Finally, a correct evaluation system is one of the active factors in the E-Learning system and is essential in all teachinglearning processes (Khan, 2005). Unfortunately, instead of paying great attention to the improvement of the quality of education, the issue of "facilitating through the use of electronic learning system" has been taken into consideration and this can be significant harm to the body of the E-Learning system (Huang, 2000).

One aspect of quality in any educational system is its commitment to moral and value issues. In order to have a professional E-Lsystem, all users including instructors and students are expected not only to have the initial skills to enter this field but also to be committed to human values and take steps towards it.

\section{Research Limitations}

Since the data collection tool was the interviewers, this study is not error-free, like other quality research (May 1991) because sometimes the thoughts, beliefs, and opinions of the interviewers influence the research subject and the process of data collection. As far as possible, the research was attempted to go through the right process by bracketing the opinions and comments of the researchers between parentheses while collecting and analyzing the data. The research was carried out at Tehran universities. It is recommended that research is conducted in other online Iranian online learning universities in order to increase the credibility of the results.

Acknowledgment: The present study was derived from a doctoral thesis of medical education at Shahid Beheshti University of Medical Sciences, Tehran, Iran. Now, the authors and all the other people who collaborated on the research are warmly appreciated. 


\section{BIODATA and CONTACT ADDRESSES of AUTHORS}

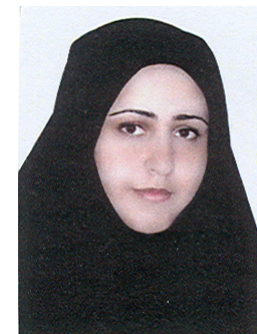

Dr. Zohrehsadat MIRMOGHTADAIE, Is an Assistant Professor of Department Of virtualization in Medical Education at Tehran University of Medical Sciences. She Gained His Ph.D. In Medical Education in 2016. Her Academic Interest Areas Are: Open And blended Learning, Medical Education Futures, E-Learning and content production In Medical Education. She is the vice dean of college and has a lot of experiences in content production.

Zohrehsadat MIRMOGHTADAIE

Adress: Tehran University of Medical Sciences, No. 2, Dolatshahi Aly., Naderi St., Keshavarz Blvd. Tehran, Iran Postal Code: 1416614741

Phone: +989133294358

Email:mirmoghtadaie@sina.tums.ac.ir

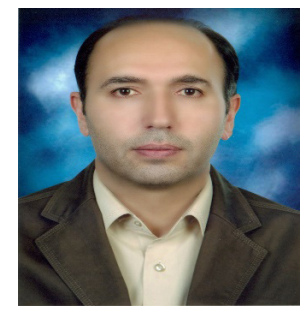

Dr. Soleiman AHMADY, is Associate Professor of Medical Education at Shahid Beheshti University of Medical Sciences. Dr. Ahmady is the vice dean of university. $\mathrm{He}$ has many Articles in medical education and virtual education.

Soleiman AHMADY

Adress: Virtual University of Medical Sciences, No 3, 1st Alley, Sarafraz St, Shahid Beheshti St.

Postal Code: 1587656811

Phone: +98912675218

Email: soleiman.ahmady@gmail.com

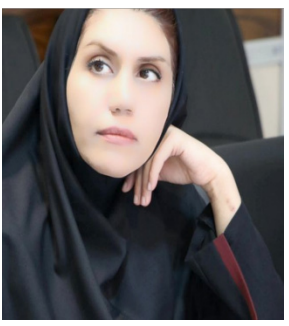

Dr. Noushin KOHAN, is An Assistant Professor Of Department Of Medical Education At Virtual University Of Medical Sciences. Dr. Kohan Gained His Ph.D. In Medical Education at July, 2016. Her Academic Interest Areas Are, Open And Distance Learning, Medical Education Futures, E-Learning, And Leadership And Management In Medical Education. She Has Over Than 15 Journal Articles Published In International Indexes.

Noushin KOHAN

Adress: Virtual University of Medical Sciences, No 3, 1st Alley, Sarafraz St, Shahid Beheshti St.

Postal Code: 1587656811

Phone: +98(21)88504051, +98(21)88504057

Email: nu.kohan@gmail.com

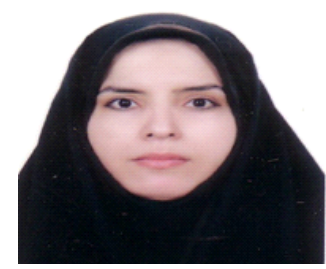

Dr. Tayebeh RAKHSHANI, is An Assistant Professor Of Department Of Health Education At Shiraz University Of Medical Sciences. Dr. Rakhshani Gained His Ph.D. In Health Education at July, 2015. Her Academic Interest Areas Are, Medical Education Futures, Health Education Models, And Patient Education. She Has Over Than 15 Journal Articles Published In International Indexes.

Tayebeh RAKHSHANI

Adress: Central building of Shiraz University of Medical Sciences, Zand St., Shiraz, Iran

Phone: +989196250473

Email: trakhshani@gmail.com 


\section{REFERENCES}

Ahmad, Z. (2010). The virtual education system (popular myth \& future reality in Pakistan).

Beqiri, M. S., Chase, N. M., \& Bishka, A. (2009). Online course delivery: An empirical investigation of factors affecting student satisfaction. Journal of Education for Business, 85(2), 95-100.

Blin, F., \& Munro, M. (2008). Why has not technology disrupted academics' teaching practices? Understanding resistance to change through the lens of activity theory. Computers \& Education, 50(2), 475-490.

Busikova, A., \& Melicherikova, Z. (2013). Ethics in E-Learning. International Association for Development of the Information Society.

Carril, P. C. M., Sanmamed, M. G., \& Selles, N. H. (2013). Pedagogical roles and competencies of university teachers practicing in the e-learning environment. The International Review of Research in Open and Distributed Learning, 14(3), 462-487.

Chickowski, E. (2005). General information, develop an IT ethics policy. Your Policy Begins Where The Low Ends, 27(20), 1-17.

Communities, C. (2001). The eLearning action plan-designing tomorrow's education.

Davis, N., \& Rose, R. (2007). Research Committee Issues Brief: Professional Development for Virtual Schooling and Online Learning. North American Council for Online Learning.

Dobrow, S. R., \& Higgins, M. C. (2005). Developmental networks and professional identity: A longitudinal study. Career Development International, 10(6/7), 567-583.

Ellaway, R. (2011). E-learning: is the revolution over? Medical Teacher, 33(4), 297-302.

Elo, S., \& Kyngas, H. (2008). The qualitative content analysis process. Journal of advanced nursing, 62(1), 107-115.

Garrett, R. K., Carnahan, D., \& Lynch, E. K. (2013). A turn toward avoidance? Selective exposure to online political information, 2004-2008. Political Behavior, 35(1), 113-134.

Gragg, J. B. B., Goodyear, R., Scheier, L., \& Krafft, L. (2016). Using Multivariate Concept Mapping to Examine Counselor Educators' Implicit Model of The Profession's Functions. The Practitioner Scholar: Journal of Counseling and Professional Psychology, 5(1).

Guba, E. G. (1981). Criteria for assessing the trustworthiness of naturalistic inquiries. Ectj, 29(2), 75.

Higgs, A. (2012). E-learning, ethics and 'non-traditional'students: Space to think aloud. Ethics and Social Welfare, 6(4), 386-402.

Holt, M. C., \& Roff, S. (2004). Development and validation of the anesthetic theatre educational environment measure (ATEEM). Medical Teacher, 26(6), 553-558.

Huang, H. M. (2000). Instructional technologies are facilitating online courses. Educational technology, 41-46.

Hung, H. T., \& Yuen, S. C. Y. (2010). Educational use of social networking technology in higher education. Teaching in higher education, 15(6), 703-714.

Khan, B. (2005). Learning features in an open, flexible and distributed environment. AACE Journal, 13(2), $137-153$.

Lai, H. J. (2011). The Influence of Adult Learners' Self-Directed Learning Readiness and Network Literacy on Online Learning Effectiveness: A Study of Civil Servants in Taiwan. Educational Technology \& Society, 14(2), 98-106.

Lemley, M. A., \& Lessig, L. (2000). The end of end-to-end: Preserving the architecture of the Internet in the broadband era. UCLa L. Rev., 48, 925. 
Lincoln, Y. S., \& Guba, E. G. (1985). Establishing trustworthiness. Naturalistic inquiry, 289, 331.

Lucas, G. R. (2017). Ethics and Cyber Warfare: The Quest for Responsible Security in the Age of Digital Warfare. Oxford University Press.

Lynch, M. M. (2002). The online educator: A guide to creating the virtual classroom. Routledge.

May, K. A. (1991). Interview techniques in qualitative research: Concerns and challenges. Qualitative nursing research: A contemporary dialogue, 188-201.

Mishna, F., Khoury-Kassabri, M., Gadalla, T., \& Daciuk, J. (2012). Risk factors for involvement in cyber bullying: Victims, bullies and bully-victims. Children and Youth Services Review, 34(1), 63-70.

Moraveji, N., Morris, M., Morris, D., Czerwinski, M., \& Henry Riche, N. (2011, May). ClassSearch: Facilitating the development of web search skills through social learning. In Proceedings of the SIGCHI Conference on Human Factors in Computing Systems (pp. 1797-1806). ACM.

Oermann, M. H. (1994). Professional nursing education in the future: Changes and challenges. Journal of Obstetric, Gynecologic, \& Neonatal Nursing, 23(2), 153-159.

Pawlina, W. (2006). Professionalism and anatomy: How do these two terms define our role? Clinical anatomy, 19(5), 391-392.

Porter, S. (2003, September). The three e's: enabling environments for everyone: E-learning and the Joint Information Systems Committee (JISC). In Interact (Vol. 26, No. 3, pp. 19-26).

Powell, A., Rabbitt, B., \& Kennedy, K. (2014). iNACOL Blended Learning Teacher Competency Framework. International Association for K-12 Online Learning.

Rhema, A., \& Miliszewska, I. (2010). Towards e-learning in higher education in Libya. Issues in Informing Science and Information Technology, 7(1), 423-437.

Salmon, G. (2004). E-moderating. Routledge.

Samdal, O., Wold, B., \& Bronis, M. (1999). Relationship between students' perceptions of school environment, their satisfaction with school and perceived academic achievement: An international study. School Effectiveness and School Improvement, 10(3), 296-320.

Sandholtz, J. H. (1997). Teaching with technology: Creating student-centered classrooms. Teachers College Press, Teachers College, Columbia University, 1234 Amsterdam Ave., New York, NY 10027.

Spinello, R. (2010). Cyberethics: Morality and law in cyberspace. Jones \& Bartlett Learning.

Svensson, L. G. (2006). New professionalism, trust and competence: Some conceptual remarks and empirical data. Current sociology, 54(4), 579-593.

Thang, S. M., Nambiar, R. M., Wong, F. F., Jaafar, N. M., \& Amir, Z. (2015). A clamour for more technology in universities: What does an investigation into the ICT use and learning styles of Malaysian 'Digital Natives' tell us? The Asia-Pacific Education Researcher, 24(2), 353-361. 